\title{
CLASSIFICANDO AÇÕES DE SUSTENTABILIDADE: UMA ANÁLISE DE CONTEÚDO DE ENTREVISTAS DE LIIDERES
}

\author{
CLASSIFYING SUSTAINABILITY ACTIONS: \\ A CONTENT ANALYSIS OF LEADERS' \\ INTERVIEWS
}

Recebido 28/12/2011 Aceito $08 / 05 / 2012$

Siqueira de Morais Neto ${ }^{1}$ Maurício Fernandes Pereira ${ }^{2}$ Emerson Antonio Maccari ${ }^{3}$

\section{RESUMO}

Esta pesquisa tem como objetivo verificar se as empresas que se apresentam como possuidoras de atitudes socioambientais o fazem por exigências legais, ou por serem pró-ativas. Dessa forma, identificam-se e classificam-se atitudes de sustentabilidade nas diversas categorias e dimensões constituintes da responsabilidade social corporativa. A perspectiva adotada considera as informações provindas dos líderes das corporações estudadas. Como metodologia, foi utilizada a análise do conteúdo de Anuários de Sustentabilidade da Revista Exame, constituindo-se de uma pesquisa descritiva, baseada em revisão bibliográfica. Para a estruturação das categorias de análise e contexto, foram utilizados os indicadores de desempenho de sustentabilidade criados pela ONG Global Reporting Initiative. De acordo com os objetivos propostos, as atitudes foram catalogadas, observando-se uma alta concentração em apenas alguns poucos temas da responsabilidade social corporativa. Verificou-se também que a maioria dessas empresas está atuando de forma pró-ativa ao benefício da humanidade e da natureza, dessa forma, fazendo mais que o mínimo para evitar penalizações. Palavras - Chave: Liderança; Sustentabilidade; Normatização; GRI

\footnotetext{
${ }^{1}$ Bacharel em Ciências da Administração pela Universidade Federal de Santa Catarina (UFSC), Mestrando pela UFSC, Florianópolis, Santa Catarina, Brasil. E-mail: smneto@hotmail.com

${ }^{2}$ Administrador e Doutor em Engenharia de Produção pela Universidade Federal de Santa Catarina - UFSC, Florianópolis, Brasil. Professor do Departamento de Ciências da Administração da UFSC, Florianópolis, Santa Catarina, Brasil. E-mail: mfpcris@gmail.com.

${ }^{3}$ Doutor em Administração pelo Programa de Pós-Graduação em Administração - PPGA da Faculdade de Economia, Administração e Contabilidade da Universidade de São Paulo - FEA/USP, Professor de Administração da Universidade Nove de Julho - UNINOVE, São Paulo - SP, Brasil. E-mail: maccari@uninove.br
} 


\section{ABSTRACT}

This research aims to determine whether companies that present themselves as having social and environmental attitudes do it for law requirements, or by being proactive. Thus, this study identifies and classifies attitudes of sustainability in the various categories and constituent dimensions of corporate social responsibility. The approach adopted considers the information coming from the leaders of the organizations studied. The methodology utilized was the content analysis of interviews of the Exame Magazine Sustainability Annuals, being a descriptive research, based on literature review. For the set of categories of analysis and context, it was used the performance indicators of sustainability, developed by the NGO Global Reporting Initiative. According to the proposed goals, attitudes have been cataloged, observing a high concentration in only a few issues of corporate social responsibility. It was found that most of these companies are acting proactively to the benefit of humanity and nature, making more than the minimum to avoid penalties. Keywords: Leadership; Sustainability; Normatization; GRI.

\section{INTRODUÇÃO}

O tema sustentabilidade está em diversas propagandas, slogans e é assunto de muitos congressos de diversas áreas, sendo que, no mundo dos negócios, fica aparente a tentativa de associação dessa ideia com a imagem que empresas querem promover para seus consumidores. Contudo, a propaganda nem sempre condiz com o que é colocado em prática. Organizações podem estar se beneficiando de uma propaganda que, na realidade, representa apenas os deverem mínimos exigidos por força legal.

A consideração que a responsabilidade social vem recebendo por parte das companhias passa para além de modismo de gestão, sendo aceita como uma prática boa e rentável por muitas dentre as principais corporações do planeta (WILLARD, 2008; HOFFMAN, 2000). Pragmaticamente, a intenção é desenvolver estratégias que reflitam o contexto único em que cada empresa opera, de modo a incorporar a sustentabilidade dentro de seus valores e de sua estratégia (PORTER, 2007).

Neste artigo, os conceitos de sustentabilidade organizacional, responsabilidade social corporativa (RSC) ou CSR (corporate social responsability) são usados como sinônimos, ou seja, representam uma forma mais ética e transparente de atuação empresarial. Na literatura especializada, não há um amplo consenso de definição desses conceitos (WBCSD, 2000; MARREWIJK, 2003; HENDERSON, 2001).

A sustentabilidade organizacional se demonstra na intenção das companhias em agregarem questões socioambientais em seus processos decisórios e a responsabilizarem-se pelas consequências de suas decisões e ações na sociedade e no meio ambiente. Para tanto, é necessário um comportamento ético e cristalino que contribua para o desenvolvimento sustentável. Portanto, as atividades de uma organização socialmente responsável devem, no mínimo, estar em conformidade com as leis e respeitar as normas internacionais.

Já a responsabilidade social corporativa implica que seus ideais estejam disseminados e integrados em toda a organização, considerando também os interesses dos diversos stakeholders da empresa: clientes, empregados, comunidades, governo, parceiros e fornecedores. Nesse sentido, o papel dos líderes, em sua busca por sustentabilidade com responsabilidade social, é garantir que as organizações operem de acordo com os princípios de desenvolvimento sustentável. A chave para organizar a empresa para uma atuação sustentável é o estabelecimento de uma cultura que visa a formular objetivos sociais e ambientais (KERR, 2006; WILLARD, 2008).

Dessa forma, questões relativas ao aprendizado e à comunicação da responsabilidade social corporativa são atribuições da ONG Global Reporting Initiative (GRI). Por meio do trabalho 
desta, existe a possibilidade de se visualizar informações sobre o tema, utilizando-se do acesso ao seu banco de dados e aos seus indicadores de desempenho de sustentabilidade. Essa organização não governamental fornece diretrizes para empresas fazerem relatórios de sustentabilidade, além de viabilizá-los depois de prontos, em seu website (GATES \& GERMAIN, 2010; BUTLER, HENDERSON \& RAIBORN, 2011). A intenção desta pesquisa é utilizar as categorias apresentadas por essa ONG, para enquadrar as atitudes de sustentabilidade declaradas pelos líderes, em suas organizações. Deste modo, pode-se ter uma perspectiva de quais são as ações que mais foram declaradas no mais importante anuário de responsabilidade social brasileiro.

Adicionalmente, utilizou-se o Guia Exame de Sustentabilidade, que é o mais popular e antigo ranking de responsabilidade social corporativa no Brasil, para a pesquisa descritiva baseada em revisão bibliográfica. Destaca-se que a Revista Exame é uma das mais importantes e influentes revistas de gestão nacional, além de já ter sido utilizada em outras investigações acadêmicas (FURTADO, NETO \& LOPES, 2007; WOOD \& PAULA, 2002).

Sendo assim, este trabalho se foca nas dimensões econômica, social e ambiental da sustentabilidade, podendo dessa forma, aprofundar-se em alguns dos aspectos do desenvolvimento sustentável. Para esta investigação, utiliza-se de uma análise de conteúdo, de entrevistas especializadas, considerando-se a perspectiva do líder.

Deste modo, o objetivo é verificar se as empresas que se apresentam como possuidoras de atitudes socioambientais o fazem por exigências legais, ou por serem pró-ativas. Considerando os argumentos apresentados, este artigo se norteia por dois objetivos específicos: (a) classificar as ações de sustentabilidade apresentadas pelas empresas nas categorias dos indicadores de desempenho da ONG Global Reporting Initiative; (b) verificar se os relatos fornecidos por parte dos líderes dizem respeito às atitudes exigidas por força de lei, ou por parte de órgãos reguladores.

\section{DESENVOLVIMENTO SUSTENTÁVEL}

Os conceitos de desenvolvimento sustentável foram inicialmente elaborados e conduzidos em 1968, quando houve a formação do Clube de Roma. Em 1972, ocorreu a primeira conferência internacional de governos para discutirem os limites dos recursos naturais no planeta, a Conferência de Estocolmo. Nesse evento, foi demonstrado que o crescimento econômico está em uma rota de colisão com a preservação ambiental (CAVALCANTI, 1998).

A interdependência da economia e do meio ambiente são importantes conceitos para políticos e tomadores de decisão ao redor do globo, tais conceitos começaram a ser seriamente discutidos na década de 1970. A Conferência das Nações Unidas sobre o Ambiente Humano na Suécia, em 1972, colocou a sustentabilidade na agenda internacional (SACHS, 1994).

A investigação sobre os riscos da degradação ambiental, chamada Limites para o Crescimento, argumenta que, caso mantenham-se os níveis de exploração no mesmo ritmo da década de 1970, o limite de desenvolvimento do planeta seria atingido em cem anos, provocando uma repentina diminuição da população mundial e da capacidade industrial (MEADOWS et al., 1972).

Nesse sentido, avançando as discussões acerca do tema, o relatório da Comissão Brundtland, promove a ideia de desenvolvimento sustentável, definindo-a como "o desenvolvimento que encontra as necessidades da geração presente, sem comprometer a habilidade das futuras gerações de atenderem suas próprias necessidades" (WCED, 1987, p.43).

Sendo assim, para se melhor compreender todas as perspectivas do conceito de desenvolvimento sustentável, Sachs (1994) apresenta cinco dimensões para a sustentabilidade: econômica, social, ambiental (ecológica), geográfica (espacial) e cultural. Entretanto, para este artigo, apenas as dimensões ambiental, social e econômica são consideradas: 
a) Sustentabilidade social entende-se como a criação de um processo de desenvolvimento que seja sustentado por outro crescimento e seja subsidiado por outra visão do que seja uma sociedade boa. A meta é construir uma civilização com maior equidade na distribuição de renda e de bens, de modo a reduzir o abismo entre o padrão de vida dos ricos e dos pobres;

b) Sustentabilidade econômica, que deve ser viabilizada através da alocação e do gerenciamento mais eficientes dos recursos e de um fluxo constante de investimentos públicos e privados. Uma condição fundamental é a de ultrapassar as configurações externas negativas resultantes do ônus do serviço da divida e da saída liquida de recursos do Hemisfério Sul, dos termos de troca desfavoráveis, das barreiras protecionistas ainda existentes no Norte e do acesso limitado à ciência e tecnologia. A eficiência econômica deve ser observada em termos macrossociais, e não somente através do critério da rentabilidade empresarial de perspectiva microeconômica;

c) A sustentabilidade ecológica (ambiental) pode ser melhorada através do uso de algumas ferramentas. Essas ações podem ocorrer através da ampliação da capacidade de carga do planeta através da criatividade, intensificando o uso de recursos com o mínimo de degradação; da limitação do consumo de combustíveis fósseis e de outros recursos não renováveis: da redução do volume de resíduos e de poluição, através da conservação de energia e recursos e da reciclagem; da promoção da autolimitação do consumo por parte de pessoas e nações; da intensificação de pesquisa para obtenção de tecnologias mais eficientes; e da definição de normas para a adequada proteção ambiental.

Essas cinco dimensões apresentam as ideias que Sachs (1994) faz do desenvolvimento dentro de um novo paradigma. Esse conceito promove ações para a melhoria nos níveis de qualidade de vida e para a preservação ambiental.

Apresentando o tema de forma sucinta, o desenvolvimento sustentável força a sociedade a pensar em termos de longo prazo e reconhecer o seu lugar dentro da biosfera (VAN BELLEN, 2005).

\section{SUSTENTABILIDADE ORGANIZACIONAL OU RESPONSABILIDADE SOCIAL CORPORATIVA}

Ambos os termos, sustentabilidade organizacional e responsabilidade social corporativa, sugerem uma atuação que considere o desenvolvimento sustentável por parte das organizações (HOFFMAN, 2000; WBCSD, 2000; MARREWIJK, 2003; HENDERSON, 2001). Ou seja, um modo diferenciado de ação, em que não somente variáveis financeiras são consideradas por parte dos tomadores de decisão.

O aumento da preocupação com meio ambiente fez crescer também a importância que gestores devem dar às questões ambientais, tendo em vista o desenvolvimento sustentável, somado à gestão dos negócios, ao assunto ecologia e ao cuidado com a vida (GRAYSON \& HODGES, 2002).

Para que as empresas contribuam para o desenvolvimento em harmonia com a natureza, as mesmas podem ter que mudar seus processos produtivos, a fim de se tornarem ecologicamente responsáveis. Isso pode implicar a construção de sistemas de produção que não causem impactos negativos e, ao mesmo tempo, que estejam ajudando para a recuperação de áreas degradadas ou oferecendo produtos e serviços que contribuam para a melhoria do desempenho ambiental dos consumidores e clientes de uma indústria (HOFFMAN, 2000).

Shrivastava (1995) afirma que uma companhia pode ser mais sustentável se não afetar o meio ambiente. Nesse caso, a sustentabilidade se insere na teoria ambiental, podendo ser alcançada quando a extração de recursos naturais ocorre dentro da capacidade de reposição natural da base de recursos e quando resíduos sólidos transferidos para os componentes físicos do sistema ecológico não ultrapassam a capacidade de resiliência dos ecossistemas. 
Quando uma companhia tem os melhores processos de tratamento de efluentes e resíduos ou utiliza tecnologias verdes, isso pode acarretar em maiores custos de produção. Se esse valor não for percebido pelos seus clientes, isso pode levar a uma queda de sua competitividade e de sua capacidade de sobreviver a médio e longo prazo, o que fere o princípio de crescimento econômico do desenvolvimento sustentável (HOFFMAN, 2000). Nesse sentido, ressalta-se a importância das empresas de melhorarem seus procedimentos e comunicarem seus procedimentos de forma honesta, considerando, pelo menos, as dimensões social, ambiental e econômica.

Contudo, se as companhias não levarem a sério essas medidas, vítimas da revolução de valores e da revolução tecnológica, poderão ser destruídas por campanhas de consumidores ativistas ou por ONGs ambientalistas, que monitoram o mercado a procura de alvos socialmente irresponsáveis (GRAYSON \& HODGES, 2002).

A empresa deve modificar os seus modelos de gestão e de tomada de decisão, considerando não somente a perspectiva econômica, mas também a social e a ambiental. Porém, a consciência e a internalização desses aspectos pela organização dependem da pressão exercida pela sociedade e pelos públicos de interesse (stakeholders), como empresas de seguro, bancos, consumidores e organizações não governamentais (HOFFMAN, 2000).

Além disso, as companhias que são capazes de orientar as suas ações estratégicas para dentro da estrutura organizacional, em seus sistemas de aprendizado, estabelecem uma sinergia entre os sistemas estratégicos e operacionais e se tornam mais sustentáveis. Ações de responsabilidade socioambiental podem trazer uma vantagem competitiva às organizações. (STARIK \& RANDS, 1995; WILLARD, 2008).

Desta forma, independentemente de uso do termo responsabilidade social corporativa ou sustentabilidade organizacional, o que se observa na literatura é a possibilidade das empresas que fazem uso desses conceitos de obterem retornos que melhorem sua competitividade.

\section{CATEGORIAS DE INDICADORES DE DESEMPENHO DE SUSTENTABILIDADE GLOBAL REPORTING INITIATIVE}

Para a realização de uma análise de conteúdo, categorias de contexto e de análise devem ser definidas (MORAES, 1999). Neste trabalho, estas são pré-definidas, e foram consideradas como categorias de contexto as seis categorias dos indicadores de desempenho de sustentabilidade GRI: ambiental; direitos humanos; práticas trabalhistas e trabalho decente; sociedade; responsabilidade pelo produto; e econômico.

Como categorias de análise são considerados apenas alguns dos aspectos destes indicadores. De um total de trinta e sete temas, vinte e nove categorias de análise foram elencadas, devido ao enquadramento com o escopo do trabalho.

Por existir um elevado número de aspectos (categorias de análise), as categorias de contexto como um todo serão definidas, e não de cada tema individualmente. Os conceitos de cada aspecto podem ser encontrados no website da GRI. Nesse sentido, abaixo se encontram as definições trazidas pelo manual de preenchimento dos relatórios de sustentabilidade, produzido por essa ONG e utilizado pelas empresas para comunicar suas ações.

\subsection{Categoria de contexto: ambiental}

As categorias de análise constituintes deste contexto são sete: materiais; energia; água; biodiversidade; emissões, efluentes e resíduos; produtos e serviços; e transporte. Destas, apenas 
um tema é considerado como obrigação legal: emissões, efluentes e resíduos. Os aspectos contidos no indicador ambiental estão estruturados de forma a refletir os insumos, as produções e o tipo de impacto que uma organização gera no meio ambiente. Energia, água e materiais representam três básicos de insumos usados pela maioria das organizações. Esses insumos resultam em produções relevantes sob o ponto de vista ambiental, que são descritas nos aspectos emissões, efluentes e resíduos (GRI, 2011).

A biodiversidade também está relacionada ao conceito de insumos na medida em que pode ser considerada um recurso natural. Contudo, a biodiversidade também sofre impactos diretos de produções, como os poluentes. Os aspectos referentes a transporte, produtos e serviços representam áreas em que uma organização pode também impactar o meio ambiente, mas, normalmente, por meio de terceiros, como clientes ou fornecedores de serviços de logística (GRI, 2011).

\subsection{Categoria de contexto: direitos humanos}

As categorias de análise presentes neste contexto são sete: práticas de investimento e políticas de compra; não discriminação; liberdade de associação e negociação coletiva; trabalho infantil; trabalho forçado ou análogo ao escravo; práticas de segurança; e direitos indígenas. Destas, seis temas são considerados como obrigação legal: não discriminação; liberdade de associação e negociação coletiva; trabalho infantil; trabalho forçado ou análogo ao escravo; práticas de segurança; e direitos indígenas.

Os indicadores de desempenho referentes a direitos humanos fornecem divulgações sobre os impactos e as atividades que uma organização tem nos direitos humanos, civis e políticos de seus stakeholders. Os aspectos dentro desses indicadores de desempenho são baseados em normas internacionalmente reconhecidas e, fundamentalmente, na Declaração Universal dos Direitos Humanos das Nações Unidas e na Declaração da Organização Internacional na Declaração sobre os Princípios e Direitos Fundamentais do Trabalho (GRI, 2011).

Os indicadores de direitos humanos enfocam como a organização mantém e respeita os direitos básicos de um ser humano, e os indicadores de práticas trabalhistas mostram a qualidade do trabalho e do ambiente de trabalho (GRI, 2011).

\subsection{Categoria de contexto: práticas trabalhistas e trabalho decente}

As categorias de análise constituintes deste contexto são quatro: relações entre trabalhadores e governança; segurança e saúde no trabalho; treinamento e educação; e diversidade e igualdade de oportunidades. Destas, apenas um tema é considerado como obrigação legal: segurança e saúde no trabalho.

A estrutura dos indicadores de práticas trabalhistas está profundamente baseada no conceito de trabalho decente. $\mathrm{O}$ conjunto de indicadores mostra a diversidade do público interno da organização, enfatizando os aspectos da distribuição por gênero e faixa etária. A abordagem de diálogo entre a organização e seus empregados, assim como o grau de organização dos funcionários em órgãos representativos também são considerados (GRI, 2011).

A proteção física e o bem-estar dos indivíduos no local de trabalho são tratados nos indicadores deferentes à segurança e à saúde no trabalho. 0 escopo dos benefícios aos empregados e das contribuições visando à ampla meta social de diversidade e igualdade de tratamento também faz parte do indicador (GRI, 2011). 


\subsection{Categoria de contexto: sociedade}

As categorias de análise deste contexto são quatro: comunidade; corrupção; políticas públicas; e concorrência desleal. Destas, dois temas são considerados como obrigação legal: corrupção; e concorrência desleal.

Neste tópico, é destacada a importância da influência de empresas na governança pública, de tomadores de decisão e de políticos sobre a questão da sustentabilidade. Além disso, os impactos sociais das organizações também estão relacionados a interações com estruturas de mercado e a instituições sociais que estabelecem o ambiente social em que grupos de stakeholders se comunicam. Essas interações, assim como a abordagem da empresa para lidar com grupos sociais, tais como as comunidades, demonstram um componente relevante do desempenho de sustentabilidade (GRI, 2011).

Os indicadores de desempenho referentes à sociedade, dessa forma, iluminam os impactos das organizações nas comunidades em que operam e as formas de gerência e mediação das interações da empresa com outras instituições sociais. Particularmente, procuram-se informações sobre suborno e corrupção, envolvimento na elaboração de políticas públicas, práticas de monopólio e conformidade com leis e regulamentos fora da esfera trabalhista e ambiental (GRI, 2011).

\subsection{Categoria de contexto: responsabilidade pelo produto}

As categorias de análise constituintes deste contexto são quatro: saúde e segurança do cliente; rotulagem de produtos e serviços; comunicações de marketing; e privacidade do cliente. Dentre elas, um tema é considerado como obrigação legal: privacidade do cliente.

O conjunto de indicadores de responsabilidade pelo produto aborda os efeitos da gestão de produtos e serviços em clientes e consumidores. Espera-se que as empresas tenham o devido cuidado na concepção de seus produtos e serviços para garantir que os mesmo sejam adequados para sua utilização pretendida e não apresentem perigos indesejados para a saúde e a segurança. Além disso, as comunicações tanto sobre os produtos e serviços quanto sobre seus usuários precisam levar em conta as necessidades de informações dos clientes e seus direitos à privacidade (GRI, 2011).

\subsection{Categoria de contexto: econômico}

As categorias de análise deste contexto são três: desempenho econômico; presença no mercado; e impactos econômicos indiretos. Contudo, nenhum tema é considerado como obrigação legal.

O desempenho econômico de uma empresa é fundamental para que essa organização e sua base para a sustentabilidade sejam entendidas. As demonstrações financeiras fornecem informações sobre a situação financeira, o desempenho e as mudanças na situação financeira de uma entidade. Apontam também os resultados atingidos na gestão do capital financeiro cedido à organização (GRI, 2011).

Nesse sentido, o fato que é relatado com menor frequência, mas geralmente desejado por usuários de relatórios de sustentabilidade, é a contribuição da organização à manutenção dos sistemas econômicos em que a empresa está inserida. Uma organização pode ser financeiramente viável, mas à custa da geração de externalidades significativas que impactam outros stakeholders. Os indicadores de desempenho econômico visam medir os resultados econômicos provenientes das atividades de uma organização e o impacto desses resultados em uma ampla gama de stakeholders (GRI, 2011). 


\section{METODOLOGIA DA PESQUISA}

Esta é uma pesquisa caracterizada como uma análise de conteúdo. Os dados secundários utilizados para a análise foram obtidos nos anuários Guia Exame de Sustentabilidade dos anos de 2007, 2008, 2009 e 2010. Essas edições foram escolhidas, pois, a partir de 2007, o anuário passou a se chamar Guia Exame de Sustentabilidade e adotou uma nova metodologia, elaborada pelo Centro de Estudos em Sustentabilidade da Fundação Getúlio Vargas. Para a categorização das unidades de análise e contexto propostas, utilizam-se os indicadores de desempenho de sustentabilidade da ONG Global Reporting Initiative.

A análise de conteúdo constitui-se em uma metodologia de pesquisa usada para descrever e interpretar o conteúdo de todo tipo de documentos e textos. Essa análise é realizada através de descrições sistemáticas, qualitativas ou quantitativas, auxiliando, assim, na reinterpretação das mensagens e na compreensão dos significados em um nível que vai além de uma leitura comum (MORAES, 1999).

Segundo Bardin (1977), a análise de conteúdo é um conjunto de técnicas de análise da comunicação. Esta intenciona, através de procedimentos sistemáticos e objetivos de descrição do conteúdo de mensagens, a obtenção de indicadores que permitam adquirir conhecimentos relativos às condições de produção ou à recepção dessas mensagens.

A análise de conteúdo pode usar como matéria-prima qualquer material provindo de comunicação, verbal ou não, como cartas, cartazes, jornais, revistas, informes, livros, relatos autobiográficos, discos, gravações, entrevistas, diários pessoais, filmes, fotografias, vídeos, dentre outros (MORAES, 1999).

De acordo com Gil (1991), do ponto de vista dos objetivos, esse tipo de pesquisa se caracteriza como descritivo. Tal modelo de investigação visa a descrever as características de determinada população ou de determinado fenômeno, podendo utilizar-se de observação sistemática. Da perspectiva dos procedimentos técnicos, este artigo é uma pesquisa bibliográfica, sendo esta elaborada a partir de material já publicado, constituído de livros, artigos de periódicos e de material disponibilizado na Internet.

Este estudo considera apenas a mensagem interpretada da citação entre aspas, emitida por parte do líder maior da organização durante a entrevista, normalmente o presidente. Contudo, são utilizadas as frases de apenas uma pessoa por entrevista, dessa forma, na ausência do presidente da empresa na matéria, considerou-se o diretor de sustentabilidade.

Sendo assim, as informações contidas nessas mensagens são interpretadas de forma a enquadrá-las em alguma das categorias de análise descritas na fundamentação teórica. A análise de conteúdo, no nível manifesto, restringe-se ao que é dito, sem buscar os significados ocultos (MORAES, 1999).

O Guia Exame de Sustentabilidade é publicado apenas uma vez por ano, o mesmo destaca as "empresas-modelo" em responsabilidade social corporativa, sendo o maior e mais respeitado levantamento sobre o tema feito no Brasil. Qualquer empresa, privada ou pública pode participar, independentemente de esta ser de capital aberto ou fechado, grande, média ou pequena. Para tanto, é necessário apenas que se inscreva gratuitamente e preencha um questionário dentro do prazo estabelecido (EDITORA ABRIL, 2011).

As perguntas estão divididas em quatro partes, que somam cerca de 140 perguntas. A primeira aborda questões sobre compromisso, transparência e governança corporativa. As demais tratam das dimensões econômico-financeira, social e ambiental. As respostas são analisadas estatisticamente, de modo a excluir empresas com os piores desempenhos em qualquer das dimensões do questionário. Com base nessas análises, vinte companhias são selecionadas para serem as "empresas-modelo" do ano (EDITORA ABRIL, 2011). 
A pesquisa do anuário é somente aplicada às maiores e mais desenvolvidas companhias do Brasil. Dessa forma, este estudo não tem a intenção de generalizar o resultado para a população total de empresas, mas sim de restringir para as chamadas "empresas-modelo". Vale ressaltar que este trabalho não utiliza uma amostra, porém considera toda a população de 80 entrevistas dos quatro anuários utilizados.

As categorias dos relatórios de sustentabilidade corporativa da Global Reporting Initiative (GRI) são usadas para formatar as unidades de análise e contexto. Esses relatórios foram inicialmente produzidos em 1997, por meio de uma iniciativa conjunta entre a organização não governamental CERES (Coalition for Environmentally Responsible Economies) e o Programa Ambiental das Nações Unidas (United Nations Environment Programme - UNEP). A instituição, que é sediada em Amsterdã, em 2002, tornou-se independente e, atualmente, é colaboradora da UNEP (GRI, 2011).

A unidade de análise é o elemento ou indivíduo unitário a ser classificado. As unidades podem ser frases, temas ou mesmo documentos em sua forma integral (MORAES, 1999). Neste trabalho, tal unidade consiste na mensagem extraída e interpretada da citação direta do líder. Contudo, se, na mesma entrevista, duas frases falam da mesma atitude, esta é considerada apenas uma vez.

Também é necessário definir a unidade de contexto. De modo geral, é uma unidade mais ampla do que a de análise, que serve de referência a esta, fixando limites contextuais para interpretá-la. Cada unidade de contexto, usualmente, contém diversas unidades de registro (MORAES, 1999).

Na Tabela 1, as unidades de contexto e suas correspondentes unidades de análise podem ser observadas e estão separadas em duas categorias, de acordo ou não com a obrigação legal ou a normatização por parte de órgãos competentes. Dentre essas unidades de análise, onze foram consideradas como atitudes mínimas de ações socioambientais das organizações. As citações que se enquadrarem nesses temas são tratadas como obrigações legais ou normatização de órgãos competentes.

Tabela 1: Unidades de análise separadas de acordo com a unidade de contexto e a obrigação legal

\begin{tabular}{|c|c|c|}
\hline direitos humanos & $\begin{array}{l}\text { 1) não discriminação; 2) liberdade de } \\
\text { associação e negociação coletiva; 3) } \\
\text { trabalho infantil; 4) trabalho forçado } \\
\text { ou análogo ao escravo; 5) práticas de } \\
\text { segurança; 6) direitos indigenas. }\end{array}$ & $\begin{array}{l}\text { 1) práticas de investimento e politicas de } \\
\text { compra }\end{array}$ \\
\hline $\begin{array}{l}\text { práticas trabalhistas e } \\
\text { trabalho decente }\end{array}$ & 1) segurança e saúde no trabalho & $\begin{array}{l}\text { 1) relações entre trabalhadores e governança; } \\
\text { 2) treinamento e educação; } 3 \text { ) diversidade e } \\
\text { igualdade de oportunidades }\end{array}$ \\
\hline $\begin{array}{l}\text { responsabilidade pelo } \\
\text { produto }\end{array}$ & 1) privacidade do cliente & $\begin{array}{c}\text { 1) saúde e segurança do cliente; 2) rotulagem } \\
\text { de produtos e serviços; } 3 \text { ) comunicações de } \\
\text { marketing }\end{array}$ \\
\hline econômico & - & $\begin{array}{l}\text { 1) desempenho econômico; 2) presença no } \\
\text { mercado; 3) impactos econômicos indiretos. }\end{array}$ \\
\hline TOTAL & 11 & 18 \\
\hline
\end{tabular}


Na presente pesquisa, a abordagem adotada é a de definição prévia das categorias de análise e contexto, além disso, foi definida uma hipótese a priori (MORAES, 1999). Ou seja, as categorias relacionadas às obrigações legais ou de entidades competentes teriam uma maior frequência de citações do que as classes que compõe atitudes socioambientais pró-ativas das organizações.

Segundo Bardin (1977), a análise de conteúdo tem uma qualidade, que é a de gestão da evidência. Ou seja, hipóteses formatadas como questões ou afirmações provisórias servem de diretrizes para o método de análise sistemática, dessa maneira, permitindo serem verificadas como verdadeiras ou falsas.

Além de observar quais atitudes são as mais citadas pelos líderes, o presente trabalho tem a intenção de verificar se existe associação entre as variáveis categoria de contexto e obrigação legal. Desse modo, pode-se observar se existem dimensões da sustentabilidade mais afetadas pela normatização ou legalidade, ou se as empresas estão sendo mais pró-ativas em algumas categorias que em outras.

Um dos grandes propósitos em pesquisas nas Ciências Sociais é indicar se uma ou mais variáveis se mostram associadas. Existe associação entre duas variáveis se o conhecimento de uma modifica a probabilidade de algum resultado da outra (BARBETTA, 2011). O teste qui-quadrado é um dos testes estatísticos mais utilizados em pesquisa social. É um método que permite testar a significância da associação entre duas variáveis qualitativas, assim como comparar a significância entre duas ou mais amostras, quando os resultados da variável resposta estão apresentados em categorias (BARBETTA, 2011).

Nesse contexto, são formuladas as seguintes hipóteses:

HO: Não existe associação entre as variáveis categorias de contexto e a obrigação legal;

H1: Existe associação entre as variáveis categorias de contexto e a obrigação legal.

Segundo Barbetta (2011), a estatística do teste, designado por $\mathrm{x}^{2}$ (qui-quadrado), é uma espécie de medida de distância entre as frequências observadas e as que se espera encontrar em cada célula de uma tabela, supondo as variáveis como independentes (HO verdadeira). No presente teste, é utilizado o nível de significância comum para as Ciências Sociais de $5 \%$.

Ainda que autores sugiram diversificadas descrições do processo da análise de conteúdo, no presente texto, constitui-se de cinco etapas (MORAES, 1999):

a) Preparação das informações;

b) Transformação do conteúdo em unidades;

c) Categorização ou classificação das unidades em categorias;

d) Descrição;

e) Interpretação.

A preparação está relacionada com identificar as diferentes amostras de informação a serem analisadas. As entrevistas foram analisadas através de um software de análise qualitativa de dados, denominado Atlas.ti. Desse modo, frases relevantes, baseadas nas citações dos líderes, que identifiquem alguma estratégia de responsabilidade social corporativa, foram destacadas e caracterizadas na demonstração final dos resultados.

Os programas de computadores podem produzir uma análise mais detalhada dos textos no que diz respeito à sua mensuração da frequência de uma determinada unidade de análise, como possibilitam também o uso de técnicas estatísticas avançadas (BARDIN, 1977).

Bardin (1977) argumenta que codificação é entendida como a escolha de unidades de registro (ou de análise), a escolha de categorias (contexto) e a seleção de regras de contagem, que são baseadas na fundamentação teórica e na metodologia deste trabalho.

Para Bardin (1977), uma das possíveis técnicas de análise de conteúdo é a categorial. A categorização é um processo de juntar dados, considerando a parte comum existente entre estes. 
Neste artigo, tal critério é semântico, ou seja, através de categorias temáticas já elaboradas pela GRI, de acordo com as dimensões econômica, social e ambiental da sustentabilidade.

Sendo assim, as categorias devem ser válidas, exaustivas e homogêneas. A classificação de qualquer unidade do conteúdo deve acontecer de forma mutuamente exclusiva. Por fim, uma classificação deve ser consistente (BARDIN, 1977; MORAES, 1999).

Depois de definidas as categorias e identificado o material constituinte de cada uma delas, é preciso comunicar output deste trabalho. Uma pesquisa de conteúdo com abordagem quantitativa envolve a organização de tabelas e quadros, apresentando não só as categorias construídas no trabalho, como também verificando as frequências e percentuais referentes às mesmas (MORAES, 1999).

A frequência de uma unidade de registro representa a importância deste. Se todos os itens forem considerados de mesmo valor, a regularidade com que esses aparecem classifica-os em mais e menos significativos (BARDIN, 1977).

Para Moraes (1999), uma interpretação baseada na fundamentação teórica claramente explicitada a priori, pode servir para a exploração dos significados expressos nas categorias da análise, em contraste com esta fundamentação.

\section{ANÁlisE E DISCUSSÃO DOS DADOS}

A intenção deste tópico é apresentar os resultados desta pesquisa, de forma a descrevêlos considerando a fundamentação teórica previamente apresentada. Portanto, os resultados são expostos, seguidos por uma consideração fundamentada de acordo com os autores que foram tomados como base para a realização deste artigo.

Foram computadas 159 mensagens, sendo classificadas nas categorias de análise e contexto, de acordo com a fundamentação proposta pelo manual da GRI. Na Tabela 2, observamse as frequências classificadas segundo a categorização proposta na metodologia.

As atitudes (unidades de análise) mais representativas no conteúdo das entrevistas foram todas as que possuem $5 \%$ ou mais do total de mensagens computadas (Tabela 2): comunidade (11\%), emissões, efluentes e resíduos (11\%), treinamento e educação (10\%), práticas de investimento e políticas de compra $(10 \%)$, produtos e serviços (10\%), materiais (8\%), energia (8\%), água (6\%) e biodiversidade (5\%).

Verifica-se que, de um total de vinte e nove temas (Tabela 2), os nove acima (cerca de $30 \%$ ) englobam juntos quase $80 \%$ do total do conteúdo analisado. Deixando, assim, para as vinte unidades de análise restantes, meros $21 \%$ do total de mensagens observadas. Sendo assim, podese dizer que as ações de sustentabilidade das empresas brasileiras estudadas encontram-se muito concentradas em apenas alguns tópicos.

Dentre essas nove categorias de análise mais representativas expostas acima, provindas de diversas unidades de contexto (dimensões da sustentabilidade), seis são do grupo ambiental, uma dos direitos humanos, uma das práticas trabalhistas e uma da sociedade. 
Tabela 2: Classificação e observação de frequências das unidades de análise

\begin{tabular}{|c|c|c|c|c|}
\hline unidade de análise & unidade de contexto & $\begin{array}{l}\text { frequência } \\
\text { observada }\end{array}$ & $\begin{array}{l}\text { frequência } \\
\text { percentual }\end{array}$ & obrigação legal \\
\hline água & ambiental & 10 & $6 \%$ & não \\
\hline biodiversidade & ambiental & 8 & $5 \%$ & não \\
\hline emissões, efluentes e residuos & ambiental & 17 & $11 \%$ & $\operatorname{sim}$ \\
\hline energia & ambiental & 13 & $8 \%$ & não \\
\hline materiais & ambiental & 12 & $8 \%$ & não \\
\hline produtos e serviços & ambiental & 16 & $10 \%$ & não \\
\hline transporte & ambiental & 2 & $1 \%$ & não \\
\hline direitos indigenas & direitos humanos & 1 & $1 \%$ & $\operatorname{sim}$ \\
\hline liberdade de associação e negociação & direitos humanos & 0 & $0 \%$ & $\operatorname{sim}$ \\
\hline não discriminação & direitos humanos & 0 & $0 \%$ & $\sin$ \\
\hline $\begin{array}{l}\text { práticas de investimento e politicas de } \\
\text { compra }\end{array}$ & direitos humanos & 16 & $10 \%$ & não \\
\hline práticas de segurança & direitos humanos & 1 & $1 \%$ & $\operatorname{sim}$ \\
\hline trabalho forçado ou análogo ao escravo & direitos humanos & 1 & $1 \%$ & $\operatorname{sim}$ \\
\hline trabalho infantil & direitos humanos & 1 & $1 \%$ & $\operatorname{sim}$ \\
\hline diversidade e igualdade de oportunidades & práticas trabalhistas & 2 & $1 \%$ & não \\
\hline relações entre trabalhadores e govemança & práticas trabalhistas & 2 & $1 \%$ & não \\
\hline segurança e saúde no trabalho & práticas trabalhistas & 2 & $1 \%$ & $\sin$ \\
\hline treinamento e educação & práticas trabalhistas & 16 & $10 \%$ & não \\
\hline comunidade & sociedade & 17 & $11 \%$ & não \\
\hline concorrência desleal & sociedade & 0 & $0 \%$ & $\operatorname{sim}$ \\
\hline corrupção & sociedade & 0 & $0 \%$ & $\operatorname{sim}$ \\
\hline politicas públicas & sociedade & 2 & $1 \%$ & não \\
\hline comunicações de marketing & $\begin{array}{c}\text { responsabilidade pelo } \\
\text { produto }\end{array}$ & 7 & $4 \%$ & não \\
\hline privacidade do cliente & $\begin{array}{l}\text { responsabilidade pelo } \\
\text { produto }\end{array}$ & 0 & $0 \%$ & $\operatorname{sim}$ \\
\hline rotulagem de produtos e serviços & $\begin{array}{l}\text { responsabilidade pelo } \\
\text { produto }\end{array}$ & 0 & $0 \%$ & não \\
\hline saúde e segurança do cliente & $\begin{array}{c}\text { responsabilidade pelo } \\
\text { produto }\end{array}$ & 2 & $1 \%$ & não \\
\hline desempenho econômico & econômico & 5 & $3 \%$ & não \\
\hline impactos econômicos indiretos & econômico & 6 & $4 \%$ & não \\
\hline presença no mercado & econômico & 0 & $0 \%$ & não \\
\hline
\end{tabular}

Nesse sentido, considerando as mesmas nove unidades de registro, apenas a emissões, efluentes e resíduos é uma obrigação legal. Esse fato pode indicar que a normatização influencia significativamente as atitudes das organizações. Porém, tal informação também mostra que há um maior número de ações representativas da população total analisada relacionadas mais à próatividade socioambiental que à obrigação legal dessas companhias.

Tabela 3: Categorias de contexto classificadas de acordo com a obrigação legal

\begin{tabular}{|c|c|c|c|c|c|c|}
\hline $\begin{array}{c}\text { categoria de } \\
\text { contexto }\end{array}$ & $\begin{array}{c}\text { frequência } \\
\text { observada }\end{array}$ & $\begin{array}{c}\text { frequência } \\
\text { percentual }\end{array}$ & $\begin{array}{c}\text { com obrigacão } \\
\text { legal }\end{array}$ & $\begin{array}{c}\text { frequência } \\
\text { percentual }\end{array}$ & $\begin{array}{c}\text { sem obrigacão } \\
\text { legal }\end{array}$ & $\begin{array}{c}\text { frequência } \\
\text { percentual }\end{array}$ \\
\hline ambiental & 78 & $49 \%$ & 17 & $11 \%$ & 61 & $38 \%$ \\
\hline $\begin{array}{c}\text { direitos } \\
\text { humanos }\end{array}$ & 20 & $13 \%$ & 4 & $3 \%$ & 16 & $10 \%$ \\
\hline $\begin{array}{c}\text { práticas } \\
\text { trabalhistas }\end{array}$ & 22 & $14 \%$ & 2 & $1 \%$ & 20 & $13 \%$ \\
\hline $\begin{array}{c}\text { sociedade } \\
\text { responsabilidade } \\
\text { pelo produto }\end{array}$ & 19 & $12 \%$ & 0 & $0 \%$ & 19 & $12 \%$ \\
\hline economico & 11 & $7 \%$ & 0 & $0 \%$ & 9 & $6 \%$ \\
\hline TOTAL & 159 & $100 \%$ & 17 & $11 \%$ & 142 & $89 \%$ \\
\hline
\end{tabular}


Continuando agora a análise na Tabela 3, verifica-se que a categoria mais relevante para os líderes é a ambiental, na qual $49 \%$ das mensagens consideram atitudes benéficas a essa dimensão da sustentabilidade. Tal categoria é seguida pelas categorias práticas trabalhistas (14\%), direitos humanos $(13 \%)$, sociedade (12\%), econômico $(7 \%)$ e responsabilidade pelo produto $(6 \%)$.

Observa-se também (Tabela 3) que as atitudes sem obrigação legal foram mais representativas em todas as categorias de contexto. Essa informação pode demonstrar uma próatividade das organizações brasileiras perante a sustentabilidade, ou seja, elas estão fazendo mais do que o mínimo exigido por normatização e leis.

Dentre todo o conteúdo analisado (Tabela 3), 89\% deste pode ser classificado como ações que não são obrigatórias às empresas, enquanto $11 \%$, de certa forma, é algo exigido por normas ou leis. Essa considerável diferença talvez possa ser explicada na maneira como os stakeholders estão começando a ser tratados pelas organizações.

$\mathrm{Na}$ dimensão ambiental (Tabela 3), verifica-se que grande parte das ações sem obrigação legal dizem respeito à inovação em produtos, em atitudes e em serviços. Diversos líderes citaram ações de redução do uso de energia e água em seus processos produtivos. Outro tema evidenciado é a troca ou o desenvolvimento de materiais ambientalmente responsáveis.

Em direitos humanos (Tabela 3), a categoria de análise práticas de investimento e políticas de compra foi muito ressaltada dentre os executivos. Essa ação demonstra o cuidado socioambiental ao escolherem seus fornecedores e investimentos, considerando a sustentabilidade em seu processo decisório. Outras ações relacionadas ao bem estar da humanidade dizem respeito ao cuidado para combater práticas como o trabalho infantil ou o trabalho indecente entre seus parceiros de negócios.

$\mathrm{Na}$ categoria práticas trabalhistas (Tabela 3 ), treinamento e educação estão em pauta entre a alta administração dessas organizações. $O$ ensino de novas funções para os funcionários e suas famílias foi citado, contudo, o fator mais representativo dessa categoria considera o condicionamento dos colaboradores a incorporarem a sustentabilidade ao seu cotidiano.

Na dimensão sociedade (Tabela 3), o envolvimento das organizações com as comunidades em que estão inseridas fica evidente. As companhias estão despertando para a necessidade de auxiliar as pessoas que vivem ao seu redor, visando a minimizar seu impacto social e, sempre que possível, fomentar práticas que diminuam a dependência das pessoas para com a economia gerada apenas pela corporação.

No que diz respeito à responsabilidade pelo produto (Tabela 3), a comunicação de marketing sobre as ações de responsabilidade social corporativa são bastante mencionadas. 0 preenchimento de relatórios de comunicação de suas atividades, considerando padrões internacionalmente reconhecidos, como o da Global Reporting Initiative, além de promover a imagem da empresa, facilita a interação entre essa e seus stakeholders.

Por último, na dimensão econômica (Tabela 3), impactos econômicos indiretos merecem destaque. Essa unidade de análise considera atitudes indiretas das empresas para fomentar comunidades locais, assim como para, de alguma forma, direcionar as ações de seus stakeholders para uma perspectiva mais sustentável. O desempenho econômico considera a contribuição da corporação à manutenção dos sistemas produtivos e econômicos em que ela se insere.

Além dos percentuais, utilizou-se o teste qui-quadrado para se tentar estabelecer uma relação entre as variáveis analisadas, este apresentou o resultado de $x^{2}=16,61$. Considerando-se o nível de significância de $5 \%$, o teste rejeita a hipótese nula (H0), em favor de $\mathrm{H} 1$, apresentada na metodologia. Em outras palavras, esse método demonstrou que há diferença entre o tipo de unidade de contexto e o tipo de obrigação legal (com ou sem).

Essa informação pode direcionar para o fato de que algumas dimensões da sustentabilidade estão sendo mais sujeitas à regulamentação que outras. 0 termo sustentabilidade pode estar 
sendo interpretado com um viés mais ambiental, fato que pode ter levado a uma legislação mais ampla nesse aspecto, refletindo em mais atitudes de respeito ao meio ambiente. Sendo assim, tal informação sugere que uma melhora na legislação de direitos trabalhistas ou de responsabilidade pelo produto, por exemplo, poderia gerar benefícios para a sociedade, pois as empresas seriam obrigadas a responder a essas exigências legais.

Outra sugestão fornecida pela análise qui-quadrado é que essas empresas estão sendo mais pró-ativas em algumas das dimensões específicas da sustentabilidade e menos em outras. Isso sugere a possibilidade das organizações conseguirem melhor retorno econômico, ao agirem sobre determinadas dimensões, que outras. Essas empresas também podem estar realizando tais atitudes de responsabilidade socioambiental de forma estratégica, ligadas ao seu core business, deixando de lado ações somente benevolentes, com as quais não teriam retorno financeiro, para praticar a responsabilidade social com retorno lucrativo.

\section{CONSIDERAÇÕES FINAIS}

Por fim, realiza-se um comentário sobre as informações levantas neste estudo. Dessa forma, espera-se poder ter contribuído com o avanço nos estudos sobre as atitudes provindas das empresas e de seus líderes que impactam os seres humanos, o meio-ambiente e economia.

Esta pesquisa, metodologicamente estruturada como uma análise de conteúdo, utilizou, para a formatação de suas categorias de análise e contexto, um instrumento criado pela entidade mundialmente reconhecida Global Reporting Initiative. Os materiais bibliográficos utilizados para a investigação constituíram-se das entrevistas dos anuários de sustentabilidade da revista Exame, especializada em gestão.

O primeiro objetivo, proposto na introdução, foi respondido à medida em que as atitudes provindas das mensagens dos líderes foram catalogadas, de acordo com os indicadores de desempenho de sustentabilidade e conforme observância de caráter legal.

A dúvida considerada no segundo objetivo, de que as empresas fazem mais ações sustentáveis devido à obrigação legal ou à normatização é refutada neste artigo. Ou seja, baseado nas informações desenvolvidas ao longo deste estudo, há evidência para acreditar que as referidas organizações estão agindo de forma pró-ativa perante a sociedade e ao meio ambiente, e não apenas de maneira a cumprir o mínimo para não sofrerem penalizações.

Observa-se também que, para que as companhias ajudem ainda mais a sociedade e a natureza, deve ocorrer uma maior distribuição de suas ações em entre os diversos temas da sustentabilidade, uma vez que as atitudes ainda se demonstram concentradas em apenas algumas dimensões.

Uma maior regulamentação e normatização por parte de entidades competentes, que considere mais aspectos da responsabilidade social, pode ser atitude desejada pela sociedade. 0 caráter ambiental das leis, devido a medidas nacionais e internacionais, apresenta-se em um nível mais avançado que a normatização de outras dimensões, principalmente a econômica. Isso se torna evidente à medida em que a especulação financeira e a desregulamentação dos mercados podem provocar sérias crises financeiras em nível global.

A atualidade se constitui em um momento oportuno para a promoção de ações em direção à transformação de processos e de atitudes. Nesse sentido, é importante considerar que muitos dos líderes, em suas entrevistas, apontam para um momento de observância a tendência socioambiental, enquanto outros dizem que uma organização que não começar a desenvolver esses aspectos brevemente não será mais competitiva. 


\section{REFERÊNCIAS BIBLIOGRÁFICAS}

BARBETTA, P. A. Estatística Aplicada às Ciências Sociais. 7a ed.2011. Florianópolis: UFSC, 2011.

BARDIN, L. Análise de conteúdo. Lisboa, Portugal: Edições 70, 1977.

BUTLER, J.; HENDERSON, S.; RAIBORN, C. Sustainability and the Balanced Scorecard: Integrating Green Measures into Business Reporting. In: Management Accounting Quaterly, vol. 12, n. 2, 2011.

CAVALCANTI, C. Desenvolvimento e natureza: estudos para uma sociedade sustentável. 2a ed.- São Paulo: Cortez; Recife, Fundação Joaquim Nabuco, 1998.

FURTADO, R. A.; NETO, A. C.; LOPES, D. P. O que as Listas de "Melhores Empresas para Trabalhar" dizem sobre as Organizações, seus Empregados e os Consultores e Pesquisadores de RH. Anais do XXXI EnANPAD. Rio de Janeiro, 2007.

GATES, S.; GERMAIN, C. Integrating Sustainability Measures into Strategic Performance Measurement Systems: An Empirical Study. In: Management Accounting Quaterly, vol. 11, n. 3, 2010.

GIL, A. Como elaborar projetos de pesquisa. São Paulo: Atlas, 1991.

GLOBAL REPORTING INITIATIVE (GRI). The G3.1 Guidelines. Recuperado em 15 de julho, 2011, de http://www.globalreporting.org/ ReportingFramework/ G31Guidelines, 2011.

GRAYSON, D.; HODGES, A. Compromisso social e gestão empresarial. São Paulo: Publifolha, 2002.

HENDERSON, D. Misguided Virtue: False Notions of Corporate Social Responsibility. New Zealand Business RoundTable: Wellington, 2001.
HOFFMAN, A.J. Environmental and Social Issues into Corporate Practice. In: Environment, vol. 42, 2000.

KERR, I. Leadership strategies for sustainable SME operation. Business Strategy and the Environment, vol15, p. 30-9, 2006.

MARREWIJK, M. Concepts and definitions of CSR and corporate sustainability: Between agency. In: Journal of Business Ethics, may, 2003.

MEADOWS, D. H.; RANDERS, J.; Behrens, W. Limits to Growth. New York, 1972

MORAES, R. Análise de conteúdo. Revista Educação. Porto Alegre, v.22, n.37, p. 7-32, 1999.

PORTER, M. Guia Exame de Sustentabilidade. "Param de Gastar Tanto Dinheiro", p. 86 - 89. Editora Abril, 2007.

EDITORA ABRIL. Revista Exame: Guia Exame Sustentabilidade. São Paulo, SP: Autor, 2007.

EDITORA ABRIL. Revista Exame: Guia Exame Sustentabilidade. São Paulo, SP: Autor, 2008.

EDITORA ABRIL. Revista Exame: Guia Exame Sustentabilidade. São Paulo, SP: Autor, 2009.

EDITORA ABRIL. Revista Exame: Guia Exame Sustentabilidade. São Paulo, SP: Autor, 2010.

EDITORA ABRIL. Revista Exame: Guia Exame Sustentabilidade. Recuperado em 16 de agosto, 2011, em http://exame.abril.com.br/ revista-exame/guia-de-sustentabilidade/2011, 2011.

SACHS, I. Desenvolvimento mundial: uma ideia sobre desenvolvimento populacional. Toulouse, Revista Internacional dos Serviços Sociais, n. 141, Unesco Erès, 1994. 
SHRIVASTAVA, P. Industrial/Environment Crises and Social Responsibility. In: Journal of SocioEconomics. V. 24, n.1, 1995.

STARIK, M.; RANDS, G. Weaving an Integrated WEB: Multilevel and Multisystem Perspectives. Academy of Management Review. V20, N4, p908-935, 1995.

VAN BELLEN, H. M. Indicadores de Sustentabilidade: Uma Análise Comparativa. 1a ed. Rio de Janeiro: Fundação Getúlio Vargas, 2005.

WOOD JR, T.; PAULA, A. P. Pop-Management. Anais do XXV EnANPAD, Campinas, 2001.

WORLD COMMISSION ON ENVIRONMENT AND DEVELOPMENT (WCED). Our common future. New York, 1987.

WORLD BUSINESS COUNCIL FOR SUSTAINABLE DEVELOPMENT (WBCSD). Corporate Social Responsibility: Making Good Business Sense. Geneva, 2000.

WILLARD, B. The Sustainability Advantage. New Society Publishers, 2008. 